
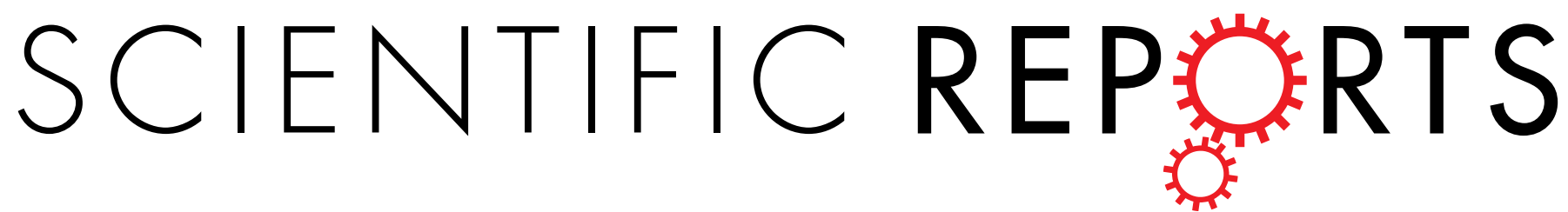

\title{
OPEN Quantitative analysis of co-oligomer formation by amyloid-beta peptide isoforms
}

Received: 07 March 2016

Accepted: 07 June 2016

Published: 27 June 2016
Marija Iljina*, Gonzalo A. Garcia*, Alexander J. Dear*, Jennie Flint", Priyanka Narayan ${ }^{\dagger}$, Thomas C. T. Michaels, Christopher M. Dobson, Daan Frenkel, Tuomas P. J. Knowles \& David Klenerman

Multiple isoforms of aggregation-prone proteins are present under physiological conditions and have the propensity to assemble into co-oligomers with different properties from self-oligomers, but this process has not been quantitatively studied to date. We have investigated the amyloid- $\beta(A \beta)$ peptide, associated with Alzheimer's disease, and the aggregation of its two major isoforms, $A \beta 40$ and $A \beta 42$, using a statistical mechanical modelling approach in combination with in vitro singlemolecule fluorescence measurements. We find that at low concentrations of $A \beta$, corresponding to its physiological abundance, there is little free energy penalty in forming co-oligomers, suggesting that the formation of both self-oligomers and co-oligomers is possible under these conditions. Our model is used to predict the oligomer concentration and size at physiological concentrations of $A \beta$ and suggests the mechanisms by which the ratio of $A \beta 42$ to $A \beta 40$ can affect cell toxicity. An increased ratio of $A \beta 42$ to $A \beta 40$ raises the fraction of oligomers containing $A \beta 42$, which can increase the hydrophobicity of the oligomers and thus promote deleterious binding to the cell membrane and increase neuronal damage. Our results suggest that co-oligomers are a common form of aggregate when $A \beta$ isoforms are present in solution and may potentially play a significant role in Alzheimer's disease.

Neurodegenerative diseases, such as Alzheimer's disease (AD), are devastating and incurable conditions associated with the misfolding and aggregation of native monomeric proteins ${ }^{1}$. The deposition of aggregated amyloid- $\beta$ peptide $(A \beta)$ in the brain is a pathological hallmark of $A D^{2}$. $A \beta$ is formed from the cleavage of a transmembrane receptor, the amyloid precursor protein (APP), in various locations to generate peptides of varying lengths, most commonly 40 and 42 residues ( $\mathrm{A} \beta 40$ and $\mathrm{A} \beta 42)^{3}$. The $\mathrm{A} \beta 42$ isoform has an additional Ile-Ala dipeptide at its $\mathrm{C}$ terminus making it more hydrophobic and more aggregation-prone than $\mathrm{A} \beta 40^{4,5}$. Hence, while the relative ratio of the $A \beta 40$ to $A \beta 42$ in cerebrospinal fluid (CSF) is approximately 9:1, the amount of $A \beta 42$ is enriched relative to $A \beta 40$ in deposits such as amyloid plaques ${ }^{6,7}$. Moreover, some early-onset versions of $A D$ have been related to the overproduction of $\mathrm{A} \beta 42$ relative to $\mathrm{A} \beta 40^{8}$, and an increase in the ratio of $\mathrm{A} \beta 42$ to $\mathrm{A} \beta 40$ cleaved from $\mathrm{APP}$ has been correlated to increases in toxicity both in vitro and in vivo $0^{9-14}$.

Although solid fibrillar deposits of $\mathrm{A} \beta$ accumulate in $\mathrm{AD}$ brains, the major cytotoxic effects causing the earliest pathological events are associated with smaller aggregates, $A \beta$ oligomers ${ }^{15}$. Such species are formed via the association of monomeric $A \beta$ and ultimately polymerize into amyloid fibrils when the total protein concentration exceeds the critical aggregation concentration $(\mathrm{CAC})^{16}$. Due to their transient presence and low abundance, the oligomers have been difficult to characterise using conventional experimental techniques ${ }^{17}$, particularly in the systems containing multiple isoforms of $A \beta$. There have been numerous studies of the mixtures of $A \beta$ isoforms, demonstrating that $\mathrm{A} \beta 40$ and $\mathrm{A} \beta 42$ co-interact during the aggregation reaction ${ }^{18-22}$. Furthermore, there is evidence that $\mathrm{A} \beta 40$ and $\mathrm{A} \beta 42$ can form co-oligomers in vitro ${ }^{10,18}$, and on the surface of neurons ${ }^{23}$. A detailed study revealed that while $A \beta 40$ and $A \beta 42$ form separate fibrils in solution, the peptides co-interact in the early stages of $\mathrm{A} \beta$ aggregation, during primary nucleation ${ }^{24}$.

In these previous studies, it has not been possible to determine the concentration and composition of the formed self- or co-oligomeric species of $\mathrm{A} \beta 40$ and $\mathrm{A} \beta 42$. Moreover, since most biophysical studies are typically

Department of Chemistry, University of Cambridge, Lensfield Road, Cambridge CB2 1EW, UK. 'Present address: Whitehead Institute for Biomedical Research, 9 Cambridge Center, Cambridge, MA, USA. *These authors contributed equally to this work. Correspondence and requests for materials should be addressed to T.P.J.K. (email: tpjk2@cam. ac.uk) or D.K. (email: dk10012@cam.ac.uk) 


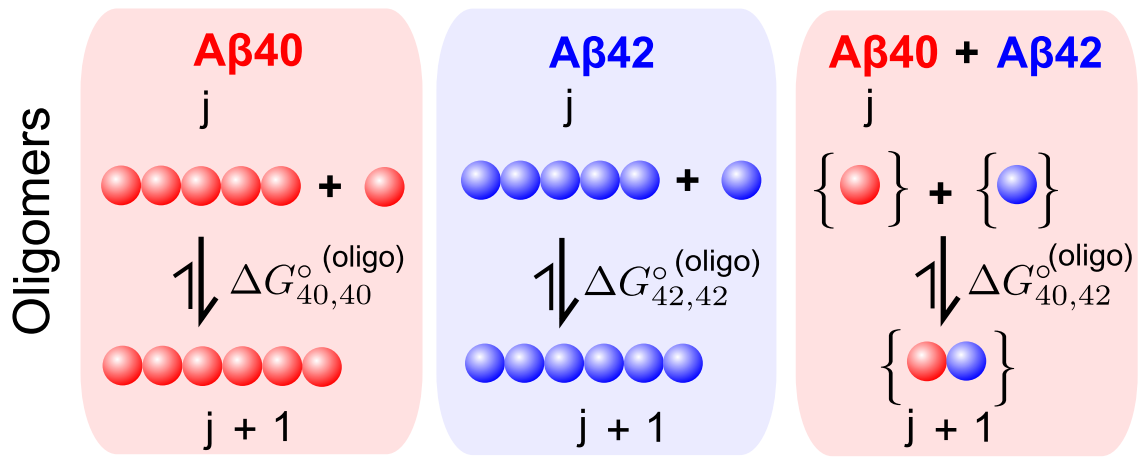

Figure 1. Schematic of the statistical mechanical model used to estimate $A \beta$ oligomer numbers and relative composition. For the single-species datasets, the model considers oligomers of any length, whereas for the co-oligomerising datasets it considers monomers and dimers as the single-species analysis predicts a very low number of oligomers larger than dimers (Fig. 3b).

performed at non-physiological high-micromolar concentrations of $\mathrm{A} \beta$, it has not been possible to extrapolate the observations to very low total concentrations of $\mathrm{A} \beta$ peptide observed in vivo ${ }^{25}$. Because of the demonstrated strong and non-linear concentration dependence of $A \beta$ aggregation ${ }^{26-29}$, a meaningful extrapolation would require direct measurements of $\mathrm{A} \beta$ oligomer populations at sub-micromolar peptide concentrations. In order to address this, we combine here direct single-molecule measurements of oligomer populations at low A $\beta$ concentrations with a statistical mechanical model to estimate the number and composition of the oligomers present under equilibrium conditions, and subsequently investigate how changing the ratios of the two A $\beta$ isoforms affects the resulting oligomer populations.

\section{Results and Discussion}

Modelling approach. In this study, the relevant thermodynamic parameter characterising oligomerization is the free energy of monomer addition, $\Delta G^{\circ}$, independent of oligomer size, and this single parameter forms the basis for our model, as described in detail in Supplementary Information.

In the model we consider the major contribution to the energetics of the oligomeric aggregates to emerge from nearest neighbour interactions. We thus treat self-oligomers as simple non-interacting one-dimensional chain structures with nearest-neighbour interactions independent of the chain length (Fig. 1). We note that the assumption of one-dimensional chain structures is not restrictive under our experimental conditions, where both self- and mixed oligomers can be inferred by our self-oligomer model to be predominantly dimeric (see Supplementary Information), and therefore larger non-linear structures where geometric effects can play a major role are not expected to perturb the analysis. This result permits us to formulate and employ a simple model for co-oligomers, containing monomers of both $\mathrm{A} \beta 40$ and $\mathrm{A} \beta 42$, which considers only dimers. The system behaviour is thus effectively governed by the Gibbs free energy $\Delta G^{\circ}$ released upon adding two monomers together to form a new intermolecular interaction. Note that while the assumption of the size-independent binding free energy is valid for the studied $\mathrm{A} \beta$ system, it is not applicable to non-filamentous growth assemblies.

In general for a linear aggregation process, we can identify $e^{\Delta G^{\circ} /(k T)}=c / c_{0}$ with a CAC $c$ for a standard concentration $c_{0}$ of $1 \mathrm{M}^{30}$. The nature of the species present at equilibrium depends strongly on the initial concentration of the monomeric peptides. When the monomer concentration is below the CAC, the majority of the peptides in the system are in their monomeric states and only a few aggregates are formed consisting of a small number of monomers. By contrast, above the CAC, most molecules are present as aggregates. These aggregates are either oligomers or fibrils. Previous single-molecule ${ }^{31}$ and bulk data ${ }^{32-34}$ indicate that these two species differ in their structures, and thus we allow for separate $\Delta G^{\circ}$ for the oligomeric and fibrillar states, $\Delta G^{\circ(\text { oligo })}$ and $\Delta G^{\circ(f i b)}$. Moreover, oligomers are populated only for small aggregation numbers, while mature fibrils are observed for sizes that exceed 1000 monomers ${ }^{35}$. At low concentrations, therefore, below the CAC, the formation of large aggregates is suppressed, and the majority of aggregates are oligomeric. When the total concentration reaches the $\mathrm{CAC}$, the majority of monomers are sequestered into fibrillar forms, and the concentration of oligomers does not increase even when the total peptide concentration is increased. Thus we expect the initial increase in aggregate concentration to be controlled by the free energy of oligomer formation $\Delta G^{\circ(\text { oligo })}$. Once the total peptide concentration reaches the CAC, $c_{0} e^{\Delta G^{o(f i b)} /(k T)}$, the theory predicts a plateau in the concentration of oligomers, controlled by the free energy of fibril formation $\Delta G^{\circ(f i b)}$. A recent study shows that the formation of self-fibrils of the $\mathrm{A} \beta$ isoforms is favoured in vitro ${ }^{24}$, which implies that there is a significant difference between the $\Delta G^{\circ(f i b)}$ when adding a monomer to a self-fibril or a fibril of different composition for $A \beta 40$ and $A \beta 42$. However, the same study suggests that the difference is smaller for $\Delta G^{o(\text { oligo) }}$ when adding a monomer to a self- or mixed oligomer.

Single-molecule measurements. Having established the described theoretical approach, we then used single-molecule two-colour coincidence detection (TCCD) ${ }^{36}$ in order to measure directly the concentration of $A \beta$ oligomers present in solutions below and around the $\mathrm{CAC}$, for $\mathrm{A} \beta 40, \mathrm{~A} \beta 42$ and a 1:1 mixture of $\mathrm{A} \beta 40$ and $\mathrm{A} \beta 42$ (see Supplementary Information for detailed methods). Prior to the measurements, it was confirmed that the 

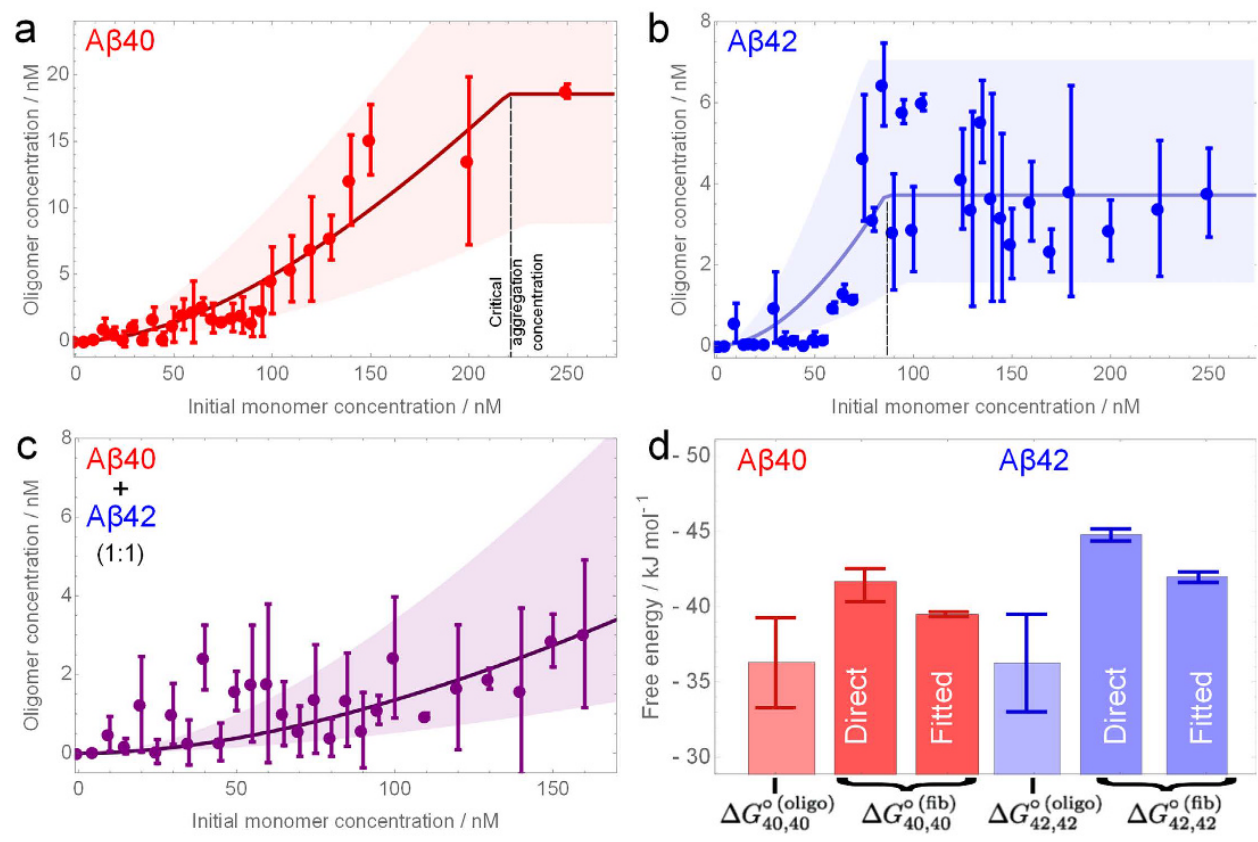

Figure 2. Equilibrium oligomer concentrations as a function of the total initial monomer concentration in the aggregation reaction. (Error bars $\mathrm{SD}, \mathrm{N}$ (samples) =3). The oligomer concentration was modelled and fitted separately for both $\mathrm{A} \beta 40$ (a), $\mathrm{A} \beta 42$ (b), and the 1:1 mixture (c); allowing extraction of the free energies of oligomerization and estimation of the CAC for A $\beta 40$ and A $\beta 42$ (fitted curves shown overlaid). The shaded bounds on these charts are curves plotted using the maximum and minimum free energies of oligomerization, and of fibril formation (given by the CAC) that still lie within the majority of the error bars. (d) The fitted free energies of oligomerization are also shown in comparison to the free energies of fibril formation obtained by direct measurement of the CAC ("Direct"), and also the free energies of fibril formation obtained from the fitted estimation of the CAC ("Fitted").

fluorescently labelled $\mathrm{A} \beta$ used in these experiments was able to self-assemble into amyloid fibrils (Supplementary Fig. S1), in agreement with our previous results ${ }^{35}$, and with multiple other studies using the same fluorescent peptides $^{23,37-39}$.

Initially, we measured the fibril CAC through two independent methods: firstly by determining the concentration of soluble species in equilibrium with fibrils, which coincides with the fibril CAC at high concentration, above the fibril CAC ${ }^{30}$ (Supplementary sections S1.4 and S2.2). Secondly, we determined the concentration at which the oligomer concentration ceases to increase with total peptide concentration and reaches a plateau phase (Supplementary sections S1.3 and S2.1); the theory predicts that this transition should take place at the fibril CAC.

The total concentration of the released species in the former approach, which corresponds to the CAC, was measured to be $94 \pm 37 \mathrm{nM}$ for $\mathrm{A} \beta 40$, and $28 \pm 4 \mathrm{nM}$ for $\mathrm{A} \beta 42$ at $\mathrm{pH} 7.4$. The value for $\mathrm{A} \beta 40$ is in good agreement with the previous result of $100 \mathrm{nM}$ at $\mathrm{pH} 7.4^{40}$, and the value for $\mathrm{A} \beta 42$ is lower than a previously reported value of $0.2 \mu \mathrm{M}$ at $\mathrm{pH} 8^{41}$, consistent with a reported decrease in CAC with lowering the $\mathrm{pH}^{40}$. This gives values of the free energy for fibril formation as $\Delta G_{42,42}^{\circ(f i b)}=-44.8 \pm 0.4 \mathrm{~kJ} \mathrm{~mol}^{-1}$ for $\mathrm{A} \beta 42$ and $\Delta G^{\circ}{ }_{40,40}=-41.7 \pm 1.1 \mathrm{~kJ} \mathrm{~mol}^{-1}$ for $A \beta 40$. The result for $A \beta 40$ is within the range of previously reported values for the unlabelled peptide ${ }^{42,43}$, which were $-37.7 \mathrm{~kJ} \mathrm{~mol}^{-1}$ and $-46.7 \mathrm{~kJ} \mathrm{~mol}^{-1}$, indicating that the presence of the fluorophore labels at the $\mathrm{N}$-terminus does not substantially alter the free energy of fibril formation. The observation that A $\beta 42$ fibrils disaggregate to a lesser extent than fibrils of $A \beta 40$ suggests that the $A \beta 42$ fibrils are more stable than their $A \beta 40$ counterparts, correlating well with previous reports of $A \beta$ disassembly and stability ${ }^{44,45}$.

Next, we combined equal quantities of monomeric peptide singly labelled with a blue-fluorophore with monomeric peptides singly labelled with a red-fluorophore, using low concentrations of total A $\beta, 1-250 \mathrm{nM}$ (Supplementary section S1.1). The solutions were left for 72 hours at $37^{\circ} \mathrm{C}$ until a steady-state population of oligomers and monomers was generated in each case. We verified that the populations of oligomers did not change upon incubation for up to 7 days (Supplementary Fig. S2) confirming the attainment of the steady-state past 72 hours. Given the chosen restriction of our incubations to up to 7 days, we do not exclude the possibility that the system could undergo further changes at longer time-scales. As the monomeric peptides self-associate to generate oligomers, we can distinguish them from monomers by the criteria of coincidence and quantify the oligomeric populations by TCCD (Supplementary section S2.1). The results are shown in Fig. 2, and the oligomer concentrations are in the range of $0-20 \mathrm{nM}$ for $\mathrm{A} \beta 40,0-4 \mathrm{nM}$ for $\mathrm{A} \beta 42$ and, strikingly, around $0-3 \mathrm{nM}$ for mixed $\mathrm{A} \beta 40$ A 342 species. We confirmed in a series of control experiments that the monitored signal arises from the interactions between the peptides and not from random association of the fluorescent probes, as detailed in Supplementary section S2.1. The error bars are relatively high in these experiments due to the low oligomer 
concentrations and inherent sample to sample variations. However, the results appear to follow the prediction from the theory and allow an estimate of the $\Delta G^{\circ(\text { oligo) }}$ values to be obtained in each case, as is described below.

Estimations of the free energies of oligomer and fibril formation. From the results in Fig. 2a,b, the similarity in the slopes of the growth regions below the CAC of the $A \beta 40$ and $A \beta 42$ self-oligomerizing systems suggests that there is no large difference in the mean free energy of oligomerization in both cases. By fitting our model to the self-oligomerizing systems (Supplementary section S6), we estimate the free energy of oligomerization for $\mathrm{A} \beta 40, \Delta G_{40,40}^{\circ}$, as $-36.3 \pm 3.0 \mathrm{~kJ} \mathrm{~mol}^{-1}$, and similarly $\Delta G_{42,42}^{\circ}$ (oligo) for $\mathrm{A} \beta 42$ as $-36.3 \pm 3.2 \mathrm{~kJ} \mathrm{~mol}^{-1}$ (Fig. 2). These values are different from those for the fibrils, which is consistent with the expected differences in the structure of oligomers and fibrils. The $\mathrm{CAC}$ for $\mathrm{A} \beta 40$ is estimated as $222 \pm 10 \mathrm{nM}$ by the same fitting procedure, and the $\mathrm{CAC}$ for $\mathrm{A} \beta 42$ is estimated as $86 \pm 10 \mathrm{nM}$; these values allow independent estimation of $\Delta G_{40,40}^{\circ(f i b)}$ as $-39.5 \pm 0.1 \mathrm{~kJ}$ $\mathrm{mol}^{-1}$ and $\Delta G_{42,42}^{\circ(f i b)}$ as $-42.0 \pm 0.3 \mathrm{~kJ} \mathrm{~mol}^{-1}$, demonstrating broad consistency with the direct measurements. The value of $\Delta G^{\circ \text { (oligo) }}$ is estimated to be $-32.6 \pm 2.6 \mathrm{~kJ} \mathrm{~mol}^{-1}$ (Supplementary section S7), and the absence of apparent plateau in the co-oligomer plot (Fig. 2c) is consistent with both isoforms being present below their CAC values. According to these results, summarized in Fig. $2 \mathrm{~d}$, in all cases the free energy of oligomerization is large and negative. The seemingly small difference in the free energy of oligomerization for the formation of co-oligomers in comparison to the self-oligomers, however, leads to lower abundance of these species, as will be described later. To point out, while there have been previous reports of the free energy for fibril formation of $A \beta^{42,43}$ and other amyloidogenic proteins ${ }^{46}$, the directly measured free energies of oligomerization for $A \beta 40, A \beta 42$ and $A \beta 40-A \beta 42$, to our knowledge, are reported for the first time. The formation of the spectator co-oligomers means that, in the presence of both $A \beta 40$ and $A \beta 42$, fewer self-oligomers of $A \beta 40$ or $A \beta 42$ will be formed, so growth into $A \beta 40$ or A 342 fibrils may be suppressed. This may provide an explanation of why the aggregation kinetics of both isoforms were observed to be mutually affected in the previous related studies ${ }^{10,18}$.

Predictions of oligomer populations at $1 \mathrm{nM}$ concentration of $\mathbf{A} \boldsymbol{\beta}$. The obtained experimental values for the free energies of oligomerization can be used to predict the total oligomer concentration and the fraction of mixed and self-oligomers at pre-defined $A \beta$ concentrations and ratios of $A \beta 40$ and $A \beta 42$. The measurements in this study have been carried out at $0-250 \mathrm{nM}$ starting concentrations of $A \beta$, the range which is substantially lower than what can be accessed using more conventional experimental methods ${ }^{17}$. However, it is known that the physiologically related total concentration of this peptide is in the range of $1-10 \mathrm{nM}^{25}$. To infer the information about oligomer types and sizes at these extremely low concentrations of $A \beta$, we can use the derived free energy values and set the starting total $\mathrm{A} \beta$ concentration to a chosen value within the physiological range. Figure 3 a shows how the distributions of oligomer sub-populations are predicted to change in $A \beta 40$ and $A \beta 42$ mixture as a function of the $A \beta 42$ proportion, when the total $A \beta$ concentration is chosen to be $1 \mathrm{nM}$. Similar predictions with the total concentrations set to $5 \mathrm{nM}$ and $10 \mathrm{nM}$ are shown in Supplementary Fig. S3. Due to less negative free energy of co-oligomerization, the resulting predicted co-oligomer populations are lower than the self-oligomer populations at all mixing ratios of $A \beta 40$ and $A \beta 42$. The predominant oligomers at a physiologically-relevant ratio of 9:1 of $A \beta 40$ to $A \beta 42$ will be the oligomers of $A \beta 40$, then a small fraction of co-oligomers with only a tiny fraction of $\mathrm{A} \beta 42$ oligomers. Moreover, the size distributions can be also inferred, as shown in Fig. 3b. At $1 \mathrm{nM}$ of the total protein concentration, the main oligomers present are dimers, and the number of oligomers is predicted to decrease exponentially with oligomer size.

Since $A \beta 42$ peptide is more hydrophobic than $A \beta 40$, it is plausible that this difference would be conserved in the derived oligomers, which could influence their properties. Our previous study suggested that $A \beta 40$ and A $\beta 42$ oligomers are both cytotoxic, once formed ${ }^{47}$. Furthermore, our previous experimental data on the binding of $A \beta 40$ and $A \beta 42$ oligomers to neuronal cells suggested that, at the lowest concentration measured, the relative affinity of A 342 oligomers for the cell membrane was 4 times that of the A $\beta 40$ oligomers $^{48}$. If we assume that the affinity of the co-oligomers is 2 times that of the $A \beta 40$ oligomers, a value intermediate between $A \beta 40$ and $A \beta 42$ oligomers, and that the majority of oligomers are dimers, according to Fig. 3b, we can then predict how the relative concentration of membrane-bound oligomers varies as a function of $A \beta 42$ proportion, as is presented in Fig. $3 c$. This analysis predicts a clear increase in the relative number of oligomers bound to the cell surface with the increase in the proportion of $A \beta 42$. Interestingly, the minimum number of cell-bound oligomers in this simulation occurs at a ratio of 9:1 of $A \beta 40$ to $A \beta 42$. Note that the oligomer size distribution (Fig. 3b) is not significantly altered by the ratios of $A \beta 40$ and $A \beta 42$ since the free energies of oligomerization are all comparable and in all cases are dominated by dimers. However, more of these dimers will contain $A \beta 42$ as the proportion of $A \beta 42$ increases. We note that while our analysis in Fig. $3 c$ considers dimers, as they are the most abundant oligomers in our system, the prediction of absolute concentrations of large surface-bound oligomers is beyond the scope of this analysis due to the absence of additional oligomer to membrane interactions.

Clearly, this model may not be fully applicable to the $\mathrm{A} \beta$ oligomers in $\mathrm{AD}$, since their formation under more complex in vivo environment is potentially affected by numerous extrinsic factors such as, for instance, the presence of small molecules and proteins, lipid surfaces, altered $\mathrm{pH}$ or ionic strength and the underlying assumption of thermodynamic equilibrium may not be correct. Nevertheless, it is interesting to compare the predictions of our model to what is actually observed in humans. From the results of a previous quantitative study where stable synthetic $A \beta$ dimers were used as standards, the concentrations of $A \beta$ oligomers in CSF of AD patients and controls were identified to be in the sub-picomolar range, in agreement with our predictions of the oligomer concentration at a total $\mathrm{A} \beta$ concentration of $1 \mathrm{nM}$, although the low concentration prevented the determination of the oligomer sizes in that work ${ }^{49}$. It is also interesting that the oligomer concentration measured in vivo appears to be determined by the $\mathrm{A} \beta$ monomer concentration in the CSF. AD patients will also have amyloid plaques containing $\mathrm{A} \beta 40$ and predominantly $\mathrm{A} \beta 42$ fibrils. In our experiments, the oligomer concentrations above fibrils 
a

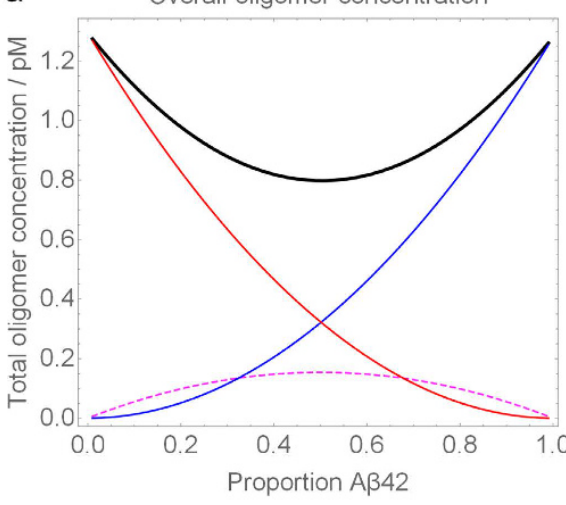

Total oligomers
A 42 oligomers

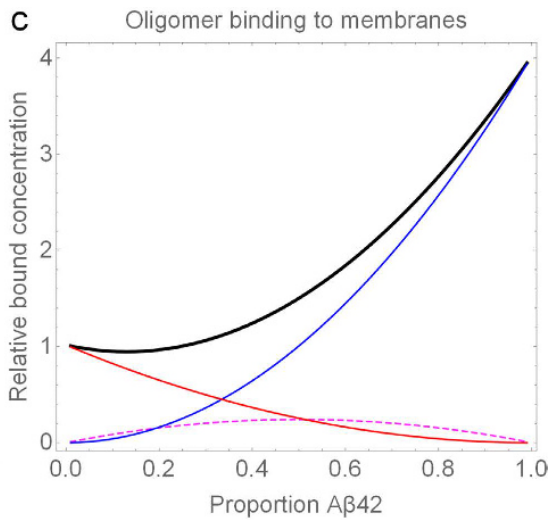

A 40 oligomers
Mixed oligomers

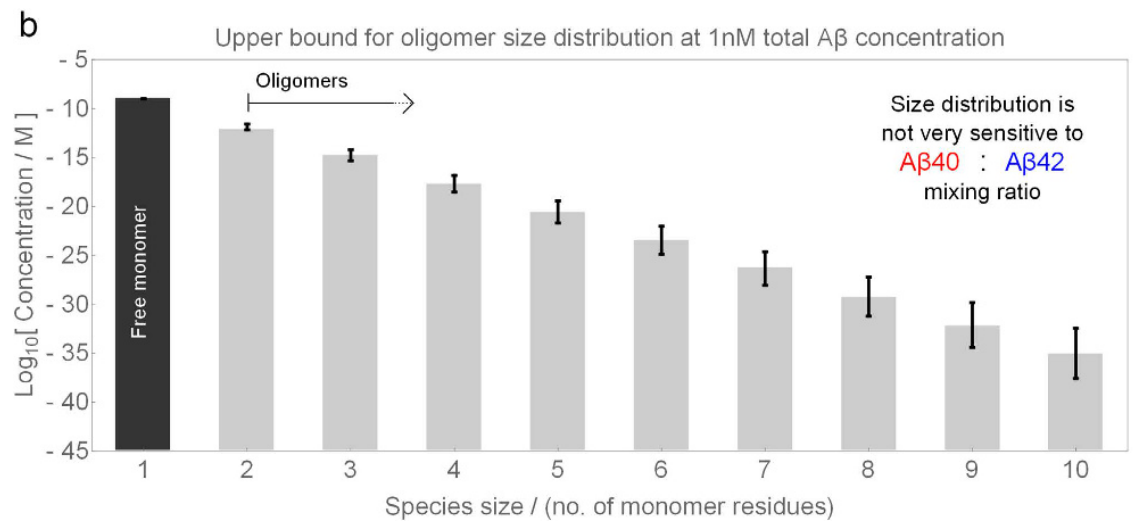

Figure 3. Simulation of $A \beta 40$ - $A \beta 42$ co-oligomerization equilibrium behaviour at a total $A \beta$ concentration of $1 \mathbf{n M}$ for a range of $\mathbf{A} \beta 42$ proportions, using $\Delta G_{40,42}^{\circ(\text { oligo })}, \Delta G_{40,40}^{\circ(\text { oligo })}, \Delta G_{42,42}^{\circ(\text { oligo })}$. Simulations at $5 \mathrm{nM}$ and $10 \mathrm{nM}$ of total $\mathrm{A} \beta$ are shown in Supplementary Fig. S3. (a) Total oligomer concentration and composition as a function of $\mathrm{A} \beta 42$ proportion. (b) Estimated concentrations of oligomers of different sizes at $1 \mathrm{nM}$ total protein concentration, calculated by assuming that $\Delta G_{40,42}^{\circ(\text { oligo })}$ is unchanged from the single-species value (in which case the ratio of $A \beta 40: A \beta 42$ is irrelevant). The true distribution will decline with oligomer size even more rapidly, as visual inspection of the data shows $\Delta G_{40,42}^{\circ \text { (oligo) }}$ to be less favourable than the single-species values. The error bars correspond to averaged uncertainty in the $\Delta G$ measurements. (c) The relative concentration of oligomers estimated to be bound to the surface of a neuronal cell, expressed relative to the concentration of oligomers bound to the surface at $1 \mathrm{nM}$ of $A \beta 40$. This result assumes that the relative affinity of co-oligomers for the cell membrane is 2 times higher than the affinity of $A \beta 40$ oligomers, and that the relative affinity of $A \beta 42$ oligomers is 4 times higher than that of $\mathrm{A} \beta 40$ oligomers.

are those shown in the plateau regions in Fig. 2. Overall the total oligomer concentration is about $20 \mathrm{nM}$, which is two orders of magnitude larger than around $0.1 \mathrm{pM}$ observed in vivo ${ }^{49}$. This suggests that either the exchange between oligomers and fibrillar plaques does not occur to any significant extent in vivo, or that there are additional contributing factors which are not present in our analysis, for example, active degradation mechanisms that remove oligomers ${ }^{50}$. To note, even though the amount of $A \beta 42$ in the CSF is generally observed to decrease in AD, our model would predict that this has little effect on the total oligomer concentration, because their population is largely dominated by $\mathrm{A} \beta 40$ oligomers. This may provide a simple explanation for why most diagnostic tests for $\mathrm{AD}$ to date based on detecting the $\mathrm{A} \beta$ oligomer concentration in CSF observe little significant difference between controls and $\mathrm{AD}$ patients ${ }^{51}$.

Our model can be applied to predict how the number of membrane-bound oligomers changes upon increasing the ratio of $A \beta 42$ to $A \beta 40$ using pre-defined concentrations of $A \beta$ which correlate with the onset of $A D$. While this analysis does not take account of any additional factors that may contribute to the disease in $\operatorname{man}^{2}$, it serves to illustrate how significantly the starting concentrations of the two isoforms influence the resulting populations of potentially pathogenic oligomers. For example, in the case of the Beyreuther/Iberian mutation ${ }^{52,53}$ where the ratio of $\mathrm{A} \beta 42$ to $\mathrm{A} \beta 40$ is as high as 22:154, early onset of $\mathrm{AD}$ occurs before 40 years of age. If we use a starting peptide ratio of 22:1 in our simulations, the number of oligomers on the cell surface is predicted to increase by a factor of 4 relative to $\mathrm{A} \beta 40$ self-oligomers. Not only can a raised proportion of $\mathrm{A} \beta 42$ be pathogenic in vivo, but also the overall overproduction of A $\beta$. For example, in Down's syndrome there is an extra copy of the gene for APP, meaning that the total $\mathrm{A} \beta$ concentration is elevated by a factor of 1.5 , leading to an early-onset $\mathrm{AD}$ at around 40 years ${ }^{55}$. If we increase the total peptide concentration by a factor of 1.5 in our model, the total $\mathrm{A} \beta$ oligomer concentration increases by $125 \%$, and the predicted number of cell-bound oligomers increases by a factor of 2.1 relative to the 
number of oligomers bound for $100 \% \mathrm{~A} \beta 40$ at the initial total $\mathrm{A} \beta$ concentration. While a change in $\mathrm{A} \beta 40$ to $\mathrm{A} \beta 42$ ratio from 9:1 to 7:3 results in no overall increase in the total number of oligomers, there is a significant difference in their predicted composition, with more co-oligomers being bound. In addition, the co-oligomers may be more persistent than self-oligomers, since they cannot grow into less toxic fibrils ${ }^{24}$, so it is possible that the increased persistency of co-oligomers additionally contributes to the increased toxicity.

\section{Summary and Conclusions}

Our results show that co-oligomers of $A \beta 40$ and $A \beta 42$ can be formed at sub-micromolar concentrations of $A \beta$ with little free energy penalty. This finding can be rationalized if there is little change in the free energy of oligomerization due to the additional Ile-Ala dipeptide on $\mathrm{A} \beta 42$, suggesting that the environment of these additional dipeptides does not change significantly between the monomeric and oligomeric state, and that the contribution to the free energy of oligomerization from the formation of contacts between other amino acids dominates the energetics relative to the role of the additional two residues at the C-terminus. There are multiple other isoforms of $\mathrm{A} \beta$ present because of truncations, mutations, ubiquitination or post-translational modifications. If there is no high penalty in the free energy of co-oligomerization, then these species may potentially be formed by various isoforms of the peptide since mixing entropy under such conditions favours the formation of mixed rather than purely segregated aggregates. It is likely therefore that under in vivo conditions where multiple isoforms are present, such mixed aggregates are prevalent. Thus, any comprehensive therapeutic strategy based on antibodies that bind $\mathrm{A} \beta$ may need to take account of the presence of co-oligomers in addition to self-oligomers of $\mathrm{A} \beta$. Therefore, it can be envisaged that in many situations both co-oligomers could be formed, which have the propensity to be more toxic due to their longer persistence time, as well as self-oligomers, which might be effective seeds and may cause prion-like spreading ${ }^{56}$. At present it is still unclear which forms of $\mathrm{A} \beta$ are the true pathogens in $\mathrm{AD}^{57}$, and the contribution of $\mathrm{A} \beta$ co-oligomers to $\mathrm{AD}$ may not have been recognized to date.

\section{Methods}

A $\beta$ peptide stock preparation. Monomeric solutions of HiLyteFluor 488 and HiLyteFluor 647-labelled $\mathrm{A} \beta 40$ and $\mathrm{A} \beta 42$ (Anaspec, Fremont) were prepared as described previously ${ }^{35,58}$, by dissolving the lyophilized peptide in $\mathrm{NaOH}, \mathrm{pH}$ 12, sonication over ice for $25 \mathrm{~min}$ (Bandelin Sonorex), and flash-freezing into aliquots and storage at $-80^{\circ} \mathrm{C}$. Initially, stock solutions were prepared by diluting the protein solutions into SSPE buffer ( $150 \mathrm{mM} \mathrm{NaCl}, 10 \mathrm{mM} \mathrm{Na}_{2} \mathrm{H}_{2} \mathrm{PO}_{4}$ x H2O, $10 \mathrm{mM} \mathrm{Na}_{2}$ EDTA, $0.01 \% \mathrm{NaN}_{3}, \mathrm{pH} 7.4$ ) followed by serial dilutions with the same SSPE buffer, $\mathrm{pH} 7.4$, to the desired aggregation reaction concentrations. Prior to the experiments, the ability of the labelled peptides to self-assemble into amyloid fibrils at $\mathrm{pH} 7.4$ was confirmed by Transmission Electron Microscopy (TEM) imaging (Supplementary Fig. S1), and was in agreement with our previous control experiments using identical peptide preparations ${ }^{35,48}$.

A $\beta$ Oligomer Preparation. For the incubations, 1:1 molar ratios of 488 and 647 -labelled samples were used, either 488:647 A $\beta 40$ or 488:647 A $\beta 42$ for the self-aggregations, or 488 A $\beta 40: 647 \mathrm{~A} \beta 42$ for the mixed aggregations. Three separate samples for each concentration ( $0-250 \mathrm{nM}$ of total $\mathrm{A} \beta$ ) and protein combination were prepared. LoBind microcentrifuge test-tubes (Eppendorf, Hamburg, Germany) were used for all incubations to prevent surface absorption, as was found to be effective in our previous studies ${ }^{59,60}$. Incubations were performed for $3 \mathrm{~d}$ at $37^{\circ} \mathrm{C}$ with rotary shaking $(200 \mathrm{rpm}$, New Brunswick Scientific Innova), and subsequently analysed using single-molecule two-colour coincidence detection (TCCD). This time period was found optimal, as the observed levels of aggregates did not change upon longer incubations (7 d), as shown in Supplementary Fig. S2.

CAC Sample Preparation. For the critical aggregation concentration (CAC) measurements using fibril disaggregation, fibrils were first prepared by 72-hour incubation of $10 \mu \mathrm{M}$ solutions of singly-labelled protein samples, either $488 \mathrm{~A} \beta 40$, or $647 \mathrm{~A} \beta 40$, and $10 \mu \mathrm{M} 488 \mathrm{~A} \beta 42$ or $647 \mathrm{~A} \beta 42$, pH-adjusted to 7.4 and incubated under the same conditions as above. Pelleting was carried out by centrifugation at $12,800 \times \mathrm{g}$ for $15 \mathrm{~min}$, followed by two identical washing steps involving removal of the supernatant, washing of the pellet and additional centrifugation for $5 \mathrm{~min}$. Finally, the pellet was re-suspended in fresh pH 7.4 SSPE buffer, by adding $100 \mu \mathrm{L}$ buffer to ensure the excess of fibrillar material. The resulting samples were incubated under quiescent conditions at $37^{\circ} \mathrm{C}$ for $3 \mathrm{~d}$, and centrifuged for $15 \mathrm{~min}$ at $12,800 \times \mathrm{g}$ prior to measurements. For the confirmation of equilibrium past $3 \mathrm{~d}$, identical samples were incubated for longer $(7 \mathrm{~d})$, yielding agreeable results.

Measurements of $\mathbf{A} \boldsymbol{\beta}$ Oligomers. Two-colour coincidence detection (TCCD) with dual excitation in 488/633 mode was performed using single-molecule confocal instrument and methodology as previously described in detail ${ }^{35}$, utilizing a detection under fast-flow, as described before ${ }^{59}$. Briefly, this method uses two overlapped lasers of different wavelengths in order to distinguish between species bearing two different fluorophores and singly-labelled species using the criteria of temporal coincidence ${ }^{35}$. Aggregates bearing two different fluorophores will produce fluorescent signals of two different colours that are coincident in time, while singly labelled monomers will produce non-coincident bursts. Full details of the experimental protocol and data analysis are in Supplementary section S2.

CAC Measurements and Analysis. These measurements were performed to determine the total concentration of $A \beta$, released from the $A \beta$ fibrils into buffer solution upon prolonged incubations, similarly to previously described methods ${ }^{35}$. This was done by relating the burst counts of the measured soluble supernatants to the burst counts from a DNA standard of precisely known concentration, as detailed in Supplementary section S2. 


\section{References}

1. Dobson, C. M. Protein folding and misfolding. Nature 426, 884-890, doi: 10.1038/nature02261 (2003).

2. Selkoe, D. J. Alzheimer's disease: genes, proteins, and therapy. Physiol Rev 81, 741-766 (2001).

3. Haass, C. Take five-BACE and the gamma-secretase quartet conduct Alzheimer's amyloid beta-peptide generation. EMBO $J$ 23, 483-488, doi: 10.1038/sj.emboj.7600061 (2004).

4. Meisl, G. et al. Differences in nucleation behavior underlie the contrasting aggregation kinetics of the A $\beta 40$ and A $\beta 42$ peptides. Proc Natl Acad Sci USA 111, 9384-9389, doi: 10.1073/pnas.1401564111 (2014).

5. Jarrett, J. T., Berger, E. P. \& Lansbury, P. T. The carboxy terminus of the beta amyloid protein is critical for the seeding of amyloid formation: implications for the pathogenesis of Alzheimer's disease. Biochemistry 32, 4693-4697 (1993).

6. Gravina, S. A. et al. Amyloid beta protein (A-beta) in Alzheimer's disease brain. Biochemical and immunocytochemical analysis with antibodies specific for forms ending at A-beta 40 or A-beta 42(43). J Biol Chem 270, 7013-7016 (1995).

7. Iwatsubo, T. et al. Visualization of A-beta $42(43)$ and A-beta 40 in senile plaques with end-specific A-beta monoclonals: evidence that an initially deposited species is A-beta 42(43). Neuron 13, 45-53 (1994).

8. Scheuner, D. et al. Secreted amyloid beta-protein similar to that in the senile plaques of Alzheimer's disease is increased in vivo by the presenilin 1 and 2 and APP mutations linked to familial Alzheimer's disease. Nat Med 2, 864-870 (1996).

9. Dahlgren, K. N. et al. Oligomeric and fibrillar species of amyloid-beta peptides differentially affect neuronal viability. J Biol Chem 277, 32046-32053, doi: 10.1074/jbc.M201750200 (2002).

10. Pauwels, K. et al. Structural Basis for Increased Toxicity of Pathological A-beta(42):A-beta(40) Ratios in Alzheimer Disease. Journal of Biological Chemistry 287, 5650-5660, doi: 10.1074/jbc.M111.264473 (2012).

11. Kuperstein, I. et al. Neurotoxicity of Alzheimer's disease A-beta peptides is induced by small changes in the A-beta(42) to A-beta(40) ratio. Embo Journal 29, 3408-3420, doi: 10.1038/emboj.2010.211 (2010).

12. Duff, K. et al. Increased amyloid-beta 42(43) in brains of mice expressing mutant presenilin 1. Nature 383, 710-713, doi: 10.1038/383710a0 (1996).

13. Citron, M. et al. Mutant presenilins of Alzheimer's disease increase production of 42-residue amyloid beta-protein in both transfected cells and transgenic mice. Nature Medicine 3, 67-72, doi: 10.1038/nm0197-67 (1997).

14. Hellstrom-Lindahl, E., Viitanen, M. \& Marutle, A. Comparison of A-beta levels in the brain of familial and sporadic Alzheimer's disease. Neurochemistry International 55, 243-252, doi: 10.1016/j.neuint.2009.03.007 (2009).

15. Haass, C. \& Selkoe, D. J. Soluble protein oligomers in neurodegeneration: lessons from the Alzheimer's amyloid beta-peptide. Nat Rev Mol Cell Biol 8, 101-112, doi: 10.1038/nrm2101 (2007).

16. Garcia, G. A., Cohen, S. I. A., Dobson, C. M. \& Knowles, T. P. J. Nucleation-conversion-polymerization reactions of biological macromolecules with prenucleation clusters. Physical Review E 89, 6, doi: 10.1103/PhysRevE.89.032712 (2014)

17. Bitan, G., Fradinger, E. A., Spring, S. M. \& Teplow, D. B. Neurotoxic protein oligomers-what you see is not always what you get. Amyloid 12, 88-95, doi: 10.1080/13506120500106958 (2005).

18. Frost, D., Gorman, P. M., Yip, C. M. \& Chakrabartty, A. Co-incorporation of A-beta 40 and A-beta 42 to form mixed pre-fibrillar aggregates. Eur J Biochem 270, 654-663 (2003).

19. Hasegawa, K., Yamaguchi, I., Omata, S., Gejyo, F. \& Naiki, H. Interaction between A-beta(1-42) and A-beta(1-40) in Alzheimer's beta-amyloid fibril formation in vitro. Biochemistry 38, 15514-15521, doi: 10.1021/bi991161m (1999).

20. Kim, J. et al. A-beta 40 inhibits amyloid deposition in vivo. Journal of Neuroscience 27, 627-633, doi: 10.1523/jneurosci.4849-06.2007 (2007).

21. Murray, M. M. et al. Amyloid-beta Protein: A-beta 40 Inhibits A-beta 42 Oligomerization. Journal of the American Chemical Society 131, 6316-+, doi: 10.1021/ja8092604 (2009)

22. Yoshiike, Y., Chui, D. H., Akagi, T., Tanaka, N. \& Takashima, A. Specific compositions of amyloid-beta peptides as the determinant of toxic beta-aggregation. Journal of Biological Chemistry 278, 23648-23655, doi: 10.1074/jbc.M212785200 (2003).

23. Johnson, R. D. et al. Single-molecule imaging reveals a $\beta 42: \mathrm{a} \beta 40$ ratio-dependent oligomer growth on neuronal processes. Biophys $J$ 104, 894-903, doi: 10.1016/j.bpj.2012.12.051 (2013).

24. Cukalevski, R. et al. The A-beta40 and A-beta42 peptides self-assemble into separate homomolecular fibrils in binary mixtures but cross-react during primary nucleation. Chem. Sci. 6, 4215-4233 (2015).

25. Mehta, P. D. et al. Plasma and cerebrospinal fluid levels of amyloid beta proteins 1-40 and 1-42 in Alzheimer disease. Arch Neurol 57, 100-105 (2000).

26. Brender, J. R. et al. Probing the sources of the apparent irreproducibility of amyloid formation: drastic changes in kinetics and a switch in mechanism due to micellelike oligomer formation at critical concentrations of IAPP. J Phys Chem B 119, 2886-2896, doi: 10.1021/jp511758w (2015).

27. Ladiwala, A. R. et al. Conformational differences between two amyloid $\beta$ oligomers of similar size and dissimilar toxicity. $J$ Biol Chem 287, 24765-24773, doi: 10.1074/jbc.M111.329763 (2012).

28. Sabaté, R. \& Estelrich, J. Evidence of the existence of micelles in the fibrillogenesis of beta-amyloid peptide. J Phys Chem B 109, 11027-11032, doi: 10.1021/jp050716m (2005).

29. Soreghan, B., Kosmoski, J. \& Glabe, C. Surfactant properties of Alzheimer's A-beta peptides and the mechanism of amyloid aggregation. J Biol Chem 269, 28551-28554 (1994).

30. Oosawa, F. \& Asakura, S. (Academic Press, New York, 1975).

31. Cremades, N. et al. Direct observation of the interconversion of normal and toxic forms of $\alpha$-synuclein. Cell 149, 1048-1059, doi: 10.1016/j.cell.2012.03.037 (2012).

32. Ahmed, M. et al. Structural conversion of neurotoxic amyloid-beta(1-42) oligomers to fibrils. Nat Struct Mol Biol 17, 561-567, doi: 10.1038/nsmb.1799 (2010).

33. Ono, K., Condron, M. M. \& Teplow, D. B. Structure-neurotoxicity relationships of amyloid beta-protein oligomers. Proc Natl Acad Sci USA 106, 14745-14750, doi: 10.1073/pnas.0905127106 (2009).

34. Fändrich, M. Oligomeric intermediates in amyloid formation: structure determination and mechanisms of toxicity. $J$ Mol Biol 421, 427-440, doi: 10.1016/j.jmb.2012.01.006 (2012).

35. Narayan, P. et al. The extracellular chaperone clusterin sequesters oligomeric forms of the amyloid- $\beta(1-40)$ peptide. Nat Struct Mol Biol 19, 79-83, doi: 10.1038/nsmb.2191 (2012).

36. Orte, A., Clarke, R. \& Klenerman, D. Single-molecule two-colour coincidence detection to probe biomolecular associations. Biochem Soc Trans 38, 914-918, doi: 10.1042/BST0380914 (2010).

37. Schauerte, J. A. et al. Simultaneous single-molecule fluorescence and conductivity studies reveal distinct classes of A-beta species on lipid bilayers. Biochemistry 49, 3031-3039, doi: 10.1021/bi901444w (2010).

38. Ding, H., Wong, P. T., Lee, E. L., Gafni, A. \& Steel, D. G. Determination of the oligomer size of amyloidogenic protein betaamyloid(1-40) by single-molecule spectroscopy. Biophys J 97, 912-921, doi: 10.1016/j.bpj.2009.05.035 (2009).

39. Johnson, R. D., Schauerte, J. A., Wisser, K. C., Gafni, A. \& Steel, D. G. Direct observation of single amyloid- $\beta(1-40)$ oligomers on live cells: binding and growth at physiological concentrations. PLos One 6, e23970, doi: 10.1371/journal.pone.0023970 (2011).

40. Brännström, K. et al. The N-terminal region of amyloid $\beta$ controls the aggregation rate and fibril stability at low pH through a gain of function mechanism. J Am Chem Soc 136, 10956-10964, doi: 10.1021/ja503535m (2014).

41. Hellstrand, E., Boland, B., Walsh, D. M. \& Linse, S. Amyloid $\beta$-protein aggregation produces highly reproducible kinetic data and occurs by a two-phase process. ACS Chem Neurosci 1, 13-18, doi: 10.1021/cn900015v (2010). 
42. O'Nuallain, B., Shivaprasad, S., Kheterpal, I. \& Wetzel, R. Thermodynamics of A-beta(1-40) amyloid fibril elongation. Biochemistry 44, 12709-12718, doi: 10.1021/bi050927h (2005).

43. Williams, A. D., Shivaprasad, S. \& Wetzel, R. Alanine scanning mutagenesis of Abeta(1-40) amyloid fibril stability. J Mol Biol 357, 1283-1294, doi: 10.1016/j.jmb.2006.01.041 (2006).

44. Sánchez, L. et al. A $\beta 40$ and A $\beta 42$ amyloid fibrils exhibit distinct molecular recycling properties. J Am Chem Soc 133, 6505-6508, doi: $10.1021 /$ ja1117123 (2011).

45. Brorsson, A. C. et al. Intrinsic determinants of neurotoxic aggregate formation by the amyloid beta peptide. Biophys J 98, 1677-1684, doi: 10.1016/j.bpj.2009.12.4320 (2010).

46. Baldwin, A. J. et al. Metastability of native proteins and the phenomenon of amyloid formation. J Am Chem Soc 133, 14160-14163, doi: $10.1021 /$ ja2017703 (2011).

47. Narayan, P. et al. Rare Individual Amyloid-beta Oligomers Act on Astrocytes to Initiate Neuronal Damage. Biochemistry 53, 2442-2453, doi: 10.1021/bi401606f (2014)

48. Narayan, P. et al. Single molecule characterization of the interactions between amyloid- $\beta$ peptides and the membranes of hippocampal cells. J Am Chem Soc 135, 1491-1498, doi: 10.1021/ja3103567 (2013).

49. Hölttä, M. et al. Evaluating amyloid- $\beta$ oligomers in cerebrospinal fluid as a biomarker for Alzheimer's disease. PLos One 8, e66381, doi: 10.1371/journal.pone.0066381 (2013).

50. Hao, R. et al. Proteasomes activate aggresome disassembly and clearance by producing unanchored ubiquitin chains. Mol Cell 51, 819-828, doi: 10.1016/j.molcel.2013.08.016 (2013).

51. Yang, T. et al. A highly sensitive novel immunoassay specifically detects low levels of soluble A-beta oligomers in human cerebrospinal fluid. Alzheimer's Research \& Therapy 7, 14 (2015).

52. Lichtenthaler, S. F. et al. Mechanism of the cleavage specificity of Alzheimer's disease gamma-secretase identified by phenylalaninescanning mutagenesis of the transmembrane domain of the amyloid precursor protein. Proc Natl Acad Sci USA 96, 3053-3058 (1999).

53. Guardia-Laguarta, C. et al. Clinical, neuropathologic, and biochemical profile of the amyloid precursor protein I716F mutation. J Neuropathol Exp Neurol 69, 53-59, doi: 10.1097/NEN.0b013e3181c6b84d (2010).

54. Suárez-Calvet, M. et al. Autosomal-dominant Alzheimer's disease mutations at the same codon of amyloid precursor protein differentially alter $A \beta$ production. J Neurochem 128, 330-339, doi: 10.1111/jnc.12466 (2014).

55. Olson, M. I. \& Shaw, C. M. Presenile dementia and Alzheimer's disease in mongolism. Brain 92, 147-156 (1969).

56. Goedert, M. Neurodegeneration. Alzheimer's and Parkinson's diseases: The prion concept in relation to assembled A $\beta$, tau, and $\alpha$-synuclein. Science 349, 1255555, doi: 10.1126/science.1255555 (2015).

57. Ashe, K. H. \& Aguzzi, A. Prions, prionoids and pathogenic proteins in Alzheimer disease. Prion 7, 55-59, doi: 10.4161/pri.23061 (2013).

58. Teplow, D. B. Preparation of amyloid beta-protein for structural and functional studies. Methods Enzymol 413, 20-33, doi: 10.1016/ S0076-6879(06)13002-5 (2006).

59. Horrocks, M. H. et al. Fast flow microfluidics and single-molecule fluorescence for the rapid characterization of $\alpha$-synuclein oligomers. Anal Chem, doi: 10.1021/acs.analchem.5b01811 (2015).

60. Tosatto, L. et al. Single-molecule FRET studies on alpha-synuclein oligomerization of Parkinson's disease genetically related mutants. Sci Rep 5, 16696, doi: 10.1038/srep16696 (2015).

\section{Acknowledgements}

The authors are grateful for financial support provided by The Schiff Foundation (G.A.G. and A.J.D.), Dr. Tayyeb Hussain Scholarship (M.I.), Alzheimer's research UK (J.F) and the Frances and Augustus Newman Foundation.

\section{Author Contributions}

M.I., J.F. and P.N. performed the single-molecule fluorescence experiments. G.A.G., A.J.D. and T.C.T.M. developed the theoretical model. C.M.D. and D.F. aided with the design of the experiments and the model. D.K. and T.P.J.K. designed and supervised the study. M.I., G.A.G., A.J.D. and D.K. wrote the paper.

\section{Additional Information}

Supplementary information accompanies this paper at http://www.nature.com/srep

Competing financial interests: The authors declare no competing financial interests.

How to cite this article: Iljina, M. et al. Quantitative analysis of co-oligomer formation by amyloid-beta peptide isoforms. Sci. Rep. 6, 28658; doi: 10.1038/srep28658 (2016).

(c) (i) This work is licensed under a Creative Commons Attribution 4.0 International License. The images

or other third party material in this article are included in the article's Creative Commons license, unless indicated otherwise in the credit line; if the material is not included under the Creative Commons license, users will need to obtain permission from the license holder to reproduce the material. To view a copy of this license, visit http://creativecommons.org/licenses/by/4.0/ 